\title{
Digitalization of Public Service Delivery: A Case of Immigration and Emigration Department of Sri Lanka
}

\author{
L. A. Pavithra Madhuwanthi ${ }^{1}$ \\ Aruna Muthulingam² ${ }^{2}$
}

${ }^{2}$ Department of Public Administration, University of Sri Jayewardenepura, Sri Lanka. Email:pavithra@sjp.ac.lk

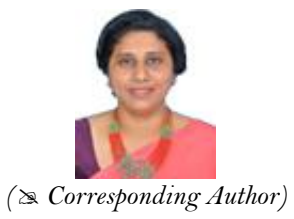

Abstract

Adaptation of digital technologies leads public sector organizations to innovate and tap their potentials. The Immigration and Emigration Department of Sri Lanka (IEDSL) has commenced digitalization of its functions during the last decade. It is one of most efficient "one-stop" service centers that cater the requirements of 2,500 citizens on a daily basis. Therefore, this paper intends to explore the adoption of digitalization in the Immigration and Emigration Department of Sri Lanka and to identify the lesson learnt from digitalization process at IEDSL. This is a qualitative study which employs the case study approach. The study uses both the primary and secondary data sources. Primary data are collected through the in-depth interviews with five senior officials involved in digitalization process at IEDSL and secondary data sources are annual performance reports, other publications and the website of the organization. The IEDSL has digitalized the entire cycle of passport issuing process. This initiation enabled the IEDSL to provide efficient service delivery by reducing public waiting time and transaction cost for the public, maintaining an equal access to the service, and making information freely available. Also, it enabled inter-link between the Immigration and Emigration Department and the Airport Authority. This paper highlighted on the lessons learnt from digitalization experience of IEDSL as robust leadership, promote employee engagement, perceive continuous development through collaborations, improving the services through introducing value added services.

Keywords: Digitalization, Public service delivery, Department of Immigration \& Emigration of Sri Lanka.

Citation | L. A. Pavithra Madhuwanthi; Aruna Muthulingam (2020). Digitalization of Public Service Delivery: A Case of Immigration and Emigration Department of Sri Lanka. Asian Journal of Social Sciences and Management Studies, 7(4): 295-300. History:

Received: 23 September 2020

Revised: 16 October 2020

Accepted: 2 November 2020

Published: 18 November 2020

Licensed: This work is licensed under a Creative Commons

Attribution 3.0 License $(\mathrm{oc})$ (E)

Publisher: Asian Online Journal Publishing Group
Acknowledgement: Both authors contributed to the conception and design of the study.

Funding: This study received no specific financial support.

Competing Interests: The authors declare that they have no conflict of interests.

Transparency: The authors confirm that the manuscript is an honest, accurate, and transparent account of the study was reported; that no vital features of the study have been omitted; and that any discrepancies from the study as planned have been explained.

Ethical: This study follows all ethical practices during writing.

\section{Contents}

1. Introduction

2. Literature Review .................296

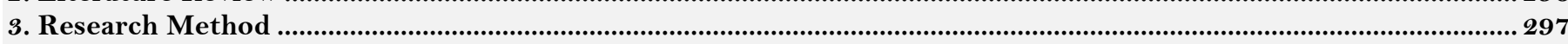

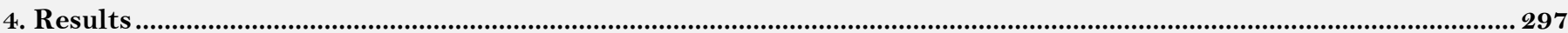

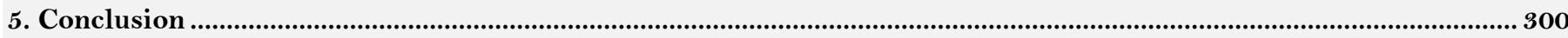

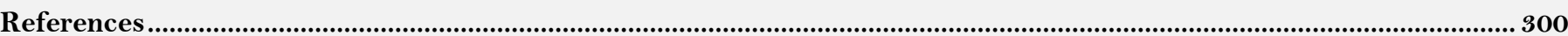




\section{Contribution of this paper to the literature}

The contribution of this paper can be explained in two ways; sharing the experience of implementing the digitalization process in a public sector institute in a developing country and the lessons gained through the digitalization process.

\section{Introduction}

Harshly impacted Covid-19 pandemic today insists the organizations and citizens across the globe to restrict their physical contacts with others. Alternatively, it encourages people to continue their personal and professional work through the digital platforms. For examples work from home, online shopping, virtual meetings, webinars have become common digital platforms which people are interacting with their fellow workers and organizations. Not only the private sector institutes but also the public sector can make use this given opportunity by lunching digitalization initiatives under its e-government agenda. These emerging digital technologies improve service efficiency and quality which are the primary goals of digital government (Layne \& Lee, 2001). Further, the adaptation of digital technologies in recent decades leads public sector organizations to innovate and tap potentials. Hence, researching on public sector digitalization initiatives and revisiting the lessons learnt has become an ardent need today, particularly in the developing country context.

The digital transformation in Sri Lanka dated back to 1980s along with the use of personal computers in the offices. Consequently, rapid use of mobile phones in the country accelerated this process at a higher pace in last decade. The government of Sri Lanka was planning to re-engineer the public sector by adopting information communication technology under the 'e-Sri Lanka' project. The Information and Communication Technology Agency in Sri Lanka has served as the data collector for many public sector organizations up until recent and then realized the strategic importance of having an integrated e-government system for public sector organizations such as registering people, immigration and emigration, elections, census and statistics, and pensions (Gunawardene, 2017).

\subsection{Problem Statement}

The Immigration and Emigration Department of Sri Lanka (IEDSL) is one of the government organizations which has successfully implemented an end-to-end digitalization and sustain service efficiency. The need for digitalization in IEDSL identified by its leadership in 2002 with a dual intention of curbing the corruptive practices that results inefficiency as well as meeting the international standards of service quality. Previously, the IEDSL operated through a decentralized channel in which the Divisional Secretariats located in districts served as the agent of receiving passport applications from citizens. It has been forwarded to the IEDSL to register and issue the passport. It is a time-consuming lengthy process and rate of application rejection is quite higher due to incomplete application. Further, the submission of the applicants' photographs was a manual process. It leads to forgeries in passport applications and challenging to trace the falsification by IEDSL. These challenges were more complicated along with the prevalence of overlapping yet defragmented authorities of public sector organizations. For instance, the IEDSL has to verify the registration of birth of applicants and their national identity card. These details are administrated by two different public organizations namely, Registrar General's Department and Department for Registration of Persons. It calls for high level of coordination between these organizations, in order to minimize forgeries. The manual administration of applicants' photographs was misused by certain local groups to facilitate criminals and culprits to obtain forged passports.

At the very beginning, it was challenging the transformation of traditional public service into digitalization. The adoption of digitalization process enabled the IEDSL to use new technologies to serve citizen and businesses efficiently and open-up convenient access to government information (Dissanayake, 2011). Adapting of Electronic Governance (e-governance) practices in Sri Lanka played a vital role in restoring the lost public trust and reenergizing transparency (Irfan, 2017). Further, the continuation of process improvement has strengthened by the ' $e-$ Sri Lanka' program, national development initiative of the Government of Sri Lanka to improve the public services and thereby uplift the quality of life of citizens (Karunasena \& Deng, 2012). Accordingly, IEDSL is the one of the efficient "one-stop" service centers in the public sector that caters the requirements of 2,500 citizens on a daily basis. Therefore, the objective of this paper is to explore the adoption of digitalization in the Immigration and Emigration Department of Sri Lanka and to identify the lesson learnt from digitalization process at IEDSL. The Global E-Government Survey reveals that, in leading countries e-government has reached sophistication, while in other countries, going digital remains relatively new (United Nations, 2020). However, Sri Lanka is striving hard to implement digitalization in public sector organizations where IEDSL is one such successful example.

The remaining sections of the paper are organized as follows. Subsequent section described the literature review, followed by the research method. Successively, results of the study are presented and concluded.

\section{Literature Review}

Distinguishing the terms 'digitization' from 'digitalization' is crucial in the contemporary information era. Digitization is the process of converting analogue streams of information into digital bits ( 1 and 0 ) while digitalization is adoption of digital technologies into the domains of social and human activities and making the people restructured around digital communication and digital media infrastructures (Gunawardene, 2017). As authors have mentioned the scope of digitization deals at micro level, analogue and digital signals, binary states, signal sampling, algorithms, signal interpretation; signal storage material, electrical components yet digitalization is much broader area that works at macro level, digital media infrastructure, communication platforms, social structure, cultural aspects, networked society; human-centered, knowledge production and management (Schumachera, Erolb, \& Sihna, 2016). Briefly it can be stated that digitizing is a technical process of converting analogue signals into a digital form whereas digitalization is a socio-technical process of applying digitizing technologies to broader social and institutional contexts (Tilson, Lyytinen, \& Sørensen, 2010). Hence, the digitalization can change a business model and generate more value producing opportunities with new revenue sources (Schumachera et al., 2016). 
Emerging digital technological advancements may lead to facilitate digital government via improving efficiency and service quality by reducing service lead times, increasing transparency, and offering seamless service provision across organizations (Layne \& Lee, 2001). Also, web-based technological development of government organizations and large-scale use of emails for external communication avoided physical encounter of citizengovernment agency and changed the nature and shape of citizen-government agency relationship. Earlier public service provision was obtained by the citizens in person, by letter or over the phone, whereas digitalization replaced that encounter via various channels such as e-mail, mobile applications, searching for information, online forms for data submission, video-based meetings with public officials (Lindgren \& Jansson, 2013). Hence, it can be stated that the conventional bureaucratic public service has been completely transformed into digital screen level bureaucracy, enabling a fast, secured and corruption-free service provision. As Jansson and Erlingsson (2014) argued that digitalization promotes democratic values like rule of law in Weberian model performing the tasks neutral and predictable manner though standardized and clearly defined rules and regulations.

However, the double nature of digitalization in public service delivery appears to have some problematic areas as well. Though policy makers and administrators are often in the view of that information and communication technology reduces bureaucratic systems, cuts down costs and provides equal treatment to citizens, such technology generates several issues such as requirements of IT skills for users, physical access, unequal outcomes to the citizens and also excessive computerization may cause to digital rigidity fear among the citizens (Hansen, Lundberg, \& Syltevik, 2018). Further, digitalized bureaucratic transformation has been criticized for fully replacing human judgement with software and predefined algorithms, front line bureaucrats are disappearing completely from the organizations, diminishing of discretionary power of bureaucrats, policy making power of bureaucrats is shifted to a new set of actors such as system designers, legal policy staff and IT experts (Buffat, 2015). Hence, it could be comprehended that in the information era digitalization extends multiple benefits for the citizens but the adoption of that technology should carefully handle in order to obtain said benefits from the digitalized bureaucratic system.

\section{Research Method}

To make an exploratory study on adoption of digitalization in public service delivery a case study approach is used. Since the IEDSL has successfully implemented digitalization in public service delivery, the chosen organization would be an informative case study. The case study was carried out in 2019. The study used both the primary and secondary data sources for the analysis. Primary data were collected through the in-depth interviews with five senior officials involved in digitalization process at IEDSL. The main purpose was to capture the process of digitalization in the organization and to get their perspectives on lessons learnt lessons from that implementation. The secondary data sources were annual performance reports, other related publications and the website of the IEDSL.

\section{Results}

\subsection{Functional Scope of IEDSL}

The IEDSL has committed to be the best immigration service in the region. It was established in 1949 to implement the newly enacted Immigrants and Emigrants Act No. 20 of 1948 after gaining independent from British. Initially the department operated in Colombo Fort and regulated the departure of Ceylon citizens and others, entry of non-Ceylonese to the country. The issuance of new Ceylon passport has commenced to the Ceylonese. The Immigrants and Emigrants Act No. 20 of 1948 entrusted power to the department to regulate immigrants and emigrants of citizens and non-citizens in Sri Lankan territory. The core functions of the departments include the tasks of issuing passports for Sri Lankans, issuing visas for foreigners, granting Sri Lankan citizenship, and border control. The expert service of this department is not merely regulating immigration, but it is inevitable to safeguard national security and facilitate development of the economy. More importantly, its commended performance is core for the development process aimed at transforming Sri Lanka in to an economic hub in Asia. The digitalization process adopted by the department streamlined the functions and remarkably contributed LKR 17,259 million to the national income in the recent year (Performance Report of IEDSL, 2018).

The organization is headed by the Controller General and responsibilities of divisions are entrusted to an Additional Controller General. Five Controllers, a Chief Accountant and an Internal Auditor serve under the direction and supervision of Additional Controller General. The Travel Division of the department is the largest in terms of its functional scope and it serve closer to the public to operationalize the vested authorities. On average, 2,500 customers visit the department daily to get the service. The passport is issued under expedited one-day service and ordinary service. Sri Lanka is one of the five countries in the world where a passport could be processed in a day (Dissanayake, 2011). As per the Performance Report of the department, it has issued 603,732 new passports in 2018. It is approximately $17 \%$ increase in past five years. Further, the demand for one-day service is higher which emphasizes the necessity of efficient and errorless service.

The adoption of digitalization in IEDSL covered the set of key functions including, issuing of passports and granting of visas. At present, the entire cycle of passport issuing process is digitalized. According to the interviewees, this initiation enabled the department to provide efficient service delivery by curbing public waiting time and transaction cost for the public, maintaining an equal access to the service and making information freely available. On the other hand, this digitalization process decreased operation cost for the organization, ensure corruption-free environment which enhances the image of the organization. Also, it enabled inter-link between the IEDSL and the Airport Authority. Further, in aligning with the country's development agenda, the department facilitates the promotion of local and foreign investments through streamlined process management while meeting the global standards. 


\subsection{Digital Initiatives of IEDSL}

As an initial prevention mechanism, IEDSL registered the photo studios located island-wide, and enlisted those as the authorized studios to get the passport photographs. Later, it developed the digital platform to connect the authorized studios and enabling online submission of photos directly to IEDSL. At present, the department will no longer accept printed photographs. All applicants should obtain their photographs from authorized studios located island-wide or from studios established at the Head Office and Regional Offices of the Department. The applicant receives an acknowledgement note containing photo which should be submitted along with their application. The photograph submitted through online is used to identify the applicant in the queue system practiced in IEDSL. Further, the details of authorized studios are openly accessible for the general public.

Conforming to standards of the International Civil Aviation Organization, acquiring biometric data of applicants into the passport system is in practice from 2015. As per the interviewees, it is a milestone of the evolving digitalization process in IEDSL. This initiation validates the Sri Lankan passport as a standardized travel document with the international recognition. Accordingly, amendments had been made to the provisions of the Immigration and Emigration Act in 2015 enabling every applicant above 16 years of age and below 60 years of age must provide his or her fingerprints while applying for passport. Obtaining fingerprints is administrated only at the Head Office and four Regional Offices of IEDSL.

The digitalization is not merely the development of computer systems and upgrading the technological infrastructures. In this evolution, the unseen influential factor is the development of human resources and change management adapted by the IEDSL. Mainly, it revised the practice by centralizing the process under the head office and four regional offices. In other words, it withdrawn the power delegated to Divisional Secretariats. The front-officers and the middle-level officials of the head office and regional offices of IEDSL are empowered with widen decision-making powers to expedite the service delivery.

However, interviewees revealed that, centralization of the passport issuing process is accelerating the service and benefiting general public, it accumulates workload on existing staff of IEDSL. Therefore, apart from enhancing decision-making powers, the officials of IEDSL has to be motivated to be committed. The department is introduced lucrative financial benefits for its staff based on their performance. Thus, resistant to change and reluctant to adopt digitalization is prudently managed by the top-management of IEDSL. The milestones of adaptation of digitalization of passport issuing process is exhibited in the figure- 1 .

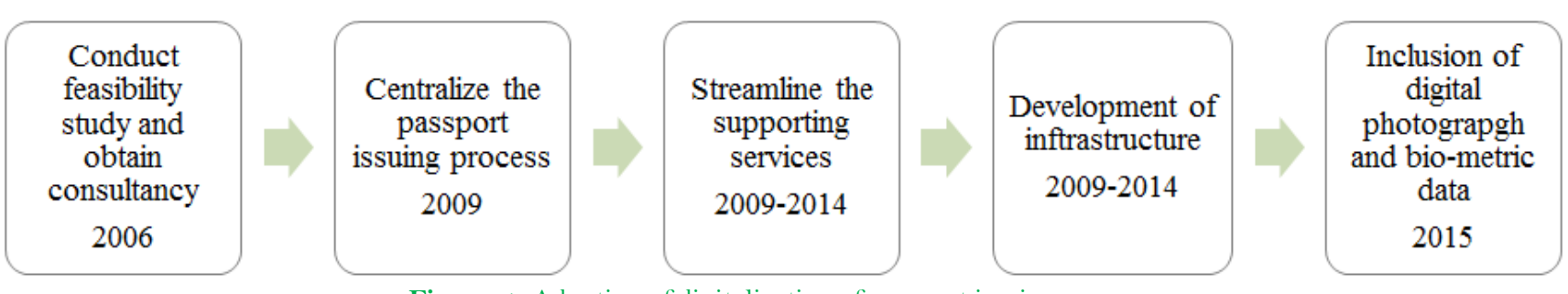

Source: Interview Data (2019)

Figure-1. Adoption of digitalization of passport issuing process.

\subsection{Process of Issuing Passport}

The issuance of passport commences with the acceptance of application. Prior to the submission of application, the applicant is guided through several sources. The information on how to apply is openly accessible by any citizens and citizens can obtain the paper-based application in head office, regional offices, divisional secretariat or in overseas Sri Lankan missions. The printable version is freely available in the department website. The process is managed by a queue system initiated through issuing a token subject to initial verification by a front-officer. The department uses the applicants' photograph directly received from the authorized studio along with the token no. to guide the applicant over service counters. The Assistant Controllers serve at the receiving points verify the supporting documents which denote the acceptance of application.

Acquiring biometric data into the passport system is a novel initiation of IEDSL implemented in 2015. Accordingly, it obtains fingerprints of applicants above 16 years of age and below 60 years. Conforming to standards of the International Civil Aviation Organization, obtain applicant photograph through the data system and capturing fingerprints promote the status of Sri Lankan passport as an internationally recognized travel document.

In order to reduce the cycle time, the simultaneous processes operated upon receiving application. The backoffice operation is commencing while the applicant provides fingerprints and then make payment. According to an interviewee, the average time taken for processing a passport under same-day service is four hours. It takes fourteen working days to issue a passport under normal service in which the passport is either sent through post or issued through foreign missions. It involves primary entry of data, validation, printing the detail page of passport and executing quality assurance and control. The use of digitalization in back-office processes facilitates to digital capturing of citizenship details and storage. Thus, the stored information is retrieved upon receiving renewal or amendment requests that lead to cut-down paper-based revalidation.

The IEDSL has encountered several challenges in adopting the digitalization of passport issuing process. In order to manage the identified challenges, the department is inculcated the culture of continuous process improvement. It enables the identification and application of strategies to successfully support the digitalization process over the period. The Table 1 summarizes such challenges and strategies applied by the IEDSL.

\subsection{Process of Issuing Visa}

Managing the process of issuing visa is vital as it regulate the legal entry of non-Sri Lankans into the country and facilitates border management. Sri Lanka is an early adopter of online visa issuance that has surpassed several developed countries. The conventional visa process is hassle prone and time-consuming process. The current mechanism of visa issuance by IEDSL is a digitalized process that enable a foreigner to apply online, make online payment of visa fee and receiving online approval of visa. As highlighted in the Performance Report of the 
department, this system immensely promoted the arrival of tourist to Sri Lanka and recorded as 2.3 million in 2018.

Table-1. Challenges faced in digitalization of passport issuance and applied strategies.

\begin{tabular}{|c|c|c|}
\hline Challenges & Applied Strategies & Status \\
\hline $\begin{array}{l}\text { Rejection rate of applications due to } \\
\text { incompleteness and other processing delays in } \\
\text { the decentralized system of service delivery }\end{array}$ & $\begin{array}{l}\text { Centralization of the process and establish the system } \\
\text { of administration supported by integrated ICT } \\
\text { systems in the department }\end{array}$ & Implemented \\
\hline $\begin{array}{l}\text { Difficulties in verifying citizenship details } \\
\text { (caused by fraudulent birth certificates and } \\
\text { identity cards) }\end{array}$ & $\begin{array}{l}\text { Interlink with third party systems which enable } \\
\text { coordination between Registrar General's Department } \\
\text { and Department for Registration of Persons }\end{array}$ & In progress \\
\hline \multirow[t]{2}{*}{$\begin{array}{l}\text { Potential reluctance of employee to adopt the } \\
\text { new digitalized environment }\end{array}$} & $\begin{array}{l}\text { Utilization of human resource management system for } \\
\text { fair work allocation and measure performance; } \\
\text { Introduce the performance-based incentive scheme }\end{array}$ & Implemented \\
\hline & Provision of skills development programmes & Continue \\
\hline \multirow{3}{*}{$\begin{array}{l}\text { Reducing waiting time and processing time } \\
\text { amidst of increasing demand for services }\end{array}$} & $\begin{array}{l}\text { Periodical review of process, time analysis and physical } \\
\text { observation }\end{array}$ & Continue \\
\hline & $\begin{array}{l}\text { Introduced the application reservation system (it } \\
\text { reduces } 30 \text { minutes on average, the time taken for the } \\
\text { submission of application) }\end{array}$ & Implemented \\
\hline & $\begin{array}{l}\text { Introduce the interconnected systems that could be } \\
\text { reduce the time taken for the data entry by } 30 \text { minutes } \\
\text { on average }\end{array}$ & In progress \\
\hline $\begin{array}{l}\text { Authentication issues related to printed } \\
\text { photographs of applicants and prevent } \\
\text { counterfeiting of passport }\end{array}$ & $\begin{array}{l}\text { Introduce studio management system through } \\
\text { registering studios, provide authentication and open- } \\
\text { up details of registered studios, connect through } \\
\text { internet based digital platform }\end{array}$ & Implemented \\
\hline $\begin{array}{l}\text { Maintain the responsive interactions with } \\
\text { citizens and uphold accountability }\end{array}$ & $\begin{array}{l}\text { Reach applicants through Short Message Service } \\
\text { (SMS) to inform the status of processing of passport; } \\
\text { Introduce the tracking system activated by using the } \\
\text { barcode of payment receipt that enables to check each } \\
\text { step of processing a passport }\end{array}$ & Implemented \\
\hline
\end{tabular}

The department introduced Electronic Travel Authorization (ETA) in 2012 with the intention of providing an efficient, reliable and simplified service to those who visit Sri Lanka for a short stay. The whole process is handled through an online portal. Further, status tracking system is included in the portal. Moreover, the data collected through ETA portal serve as a data source to analyze the tourist arrivals and facilitate policy decisions.

\subsection{Lessons Learnt from Digitalization in IEDSL}

The success of the digitalization of public services are not limited to the automation. Machine intensive office work enabled through digital systems can be merely the infrastructure. Infusion of qualities of man and the digital infrastructure results the effective service delivery. Thus, the ongoing discussion on digitalization of public services must also be discussed in terms of division of tasks between technology and humans particularly their characteristics and qualities (Lindgren, Madsen, Hofmann, \& Melin, 2019). Accordingly, the digitalization in IEDSL has been predominantly succeeded through thoughtful blend of technological and human capacities. The proceeding section highlights the lesson learnt from the IEDSL digitalization process.

\subsubsection{Robust Leadership}

Digitalization can be viewed as the change management which calls for holistic management. Thus, the leader has to manage the people, knowledge and other resources. The leader has to envisage the process developments and inspire the staff to feasibly operationalize the plans. The visionary leaderships of the Controller Generals of last two decades been proven success in creating the high-tech environment in the IEDSL. They inculcated the culture of continuous review of current practices, identify the gaps or need for development, learn the local and global trends, connect with public as well as private agencies to sustain the digitization process.

However, in many public organizations the change of leadership leads to revisal of exiting transformation process. In contrary, the IEDSL able to progress despite of change in leadership. It could have failed if it invested only on IT infrastructure. Initially the leaders embedded the innovation driven culture and continually invest on process improvements.

\subsubsection{Promote Employee Engagement}

The resistance to change is the toughest deal in adaptation of technologies in public sector. The IEDSL introduced the digital technologies not only to ensure the improvement of service quality, but also meet the employees' expectations. In other words, the adaptation of digital systems ensured benefits to the clients as well as its employees.

The IEDSL incorporated the human resource management system to measure employee performance on daily basis. The measured performance is used to provide financial incentives. Thus, system enabled, transparent incentive scheme helped to manage the resistance to change. Further, at the initial stage, IEDSL trained the employees those who are willing to change. The second group of employees those who are unwilling to change has given the time to observe the transformation. Later, they too realized the success of new systems and gradually joined the first group. According to the official, it is emphasized that, patience and understanding is needed to tap employees' potential in order to adopt technologies. 
The IEDSL invested to sharpen the skills of people through series of training and development programmes. Those focuses on improving ICT literacy, attitudinal change and knowledge enhancement.

\subsubsection{Perceive Continuous Development through Collaborations}

Generally, the digitalization of public service is administered as the gigantic step at a planned period. It demands for massive investment in terms of technological infrastructure and development of systems. It is perceived as a best destination to be, whereas in reality digital technologies become obsolete in due course. It requires continuous development and upgrade along with the novel trends.

Therefore, the IEDSL exercises process improvements by analyzing the current practices and identifying the performance gaps. Rather than taking giant steps, it generally focuses on gradual improvement of processes and innovate to improve its stages. It has been realized through third party collaborations. For instance, IEDSL is in partnership with private sector to support the in-house development of systems. It adopts the General Data Protection Regulation (EU) to protect the privacy of data and ensure healthy collaboration with third party. Further, it promotes inter-organizational coordination between local and international authorities to enable the efficient and effective service delivery. The continuity of process improvement in IEDSL supports to upheld the integrity of national passport and confirm to the international standards. For instance, capturing biometric fingerprint data from all passport applicants will address concerns related to multiple identities to implement "one person, one passport" policy.

In 2020, the preliminary activities related to introducing an e-passport that includes the high standard bio metric information to meet the standards of International Civil Aviation Organization is in progress. The ePassports will ease the foreign travel as smart machines (e-gates) at airport immigration counters could do the verification by retrieving biometric information. The traveler has to input passport data, boarding pass number and fingerprint. It will be the breakthrough in Sri Lankan public service.

\subsubsection{Improving the Services through Introducing Value Added Services}

The demand for passport services had been increase constantly along with the frequent foreign travel by Sri Lankans. On average the IEDSL received 1,200 passport applications on daily basis in 2004. At present, it has been doubled and issuance of passports recorded the 34\% increase from 2014 to 2018 (Performance Report of IEDSL, 2018). Similarly, the demand for one-day service is on rise. These trends emphasize further improvements in the passport issuing process to uphold the efficiency and manage the increasing workload. The current process depends on paper-based application and documents submitted by citizens. Thus, the authorities are focusing on enabling online submission of application to accelerate the service. In addition, IEDSL is stepped to introduce value added services which shrink the cycle time. For instance, feed priority lane that facilitates citizens to reserve an appointment at their convenient and make online payment in advance. However, establishing inter-organizational coordination is a prerequisite to enable remote authentication of citizens details in support of process development.

\section{Conclusion}

The IEDSL as a pioneer of digitalizing services in Sri Lankan public sector, progresses towards the conversion of its core functions to be delivered in web-based integrated systems. In order to sustain the success of digital initiations the IEDSL, prioritizes the continuous process development, viable collaborations and inclusion of valueadded services. For this institution, digitalization is not merely the development of systems and technologies but embed the innovation driven culture to ensure continuity of the process improvement. Thus, robust leadership and employee engagement are the other crucial factors of digitalization.

\section{References}

Buffat, A. (2015). Street-level bureaucracy and e-government. Public Management Review, 17(1), 149-161.Available at: $10.1080 / 14719037.2013 .771699$.

Dissanayake, D. M. R. (2011). Information communication technology policy of sri lanka and its impacts to socioeconomic development: A review of Sri Lankan experience. Journal of Education and Vocational Research, 1(2), 53-59.

Gunawardene, N. (2017). Digital transformation in Sri Lanka: Opportunities and challenges in pursuit of liberal policies. Sri Lanka: Friedrich Naumann Foundation.

Hansen, H. T., Lundberg, K., \& Syltevik, L. J. (2018). Digitalization, street-level bureaucracy and welfare users' experiences. Social Policy and Administration, 52(1), 67-90.

Irfan, M. I. M. (2017). The role of e-governance in administrative efficiency and combating corruption: Case of Sri Lanka. Global Journal of Management and Business Research, 17(2), 38-50.

Jansson, G., \& Erlingsson, G. Ó. (2014). More e-government, less street-level bureaucracy? on legitimacy and the human side of public administration. Journal of Information Technology \& Politics, 11(3), 291-308.Available at: 10.1080/19331681.2014.908155.

Karunasena, K., \& Deng, H. (2012). Critical factors for evaluating the public value of e-government in Sri Lanka. Government Information Quarterly, 29(1), 76-84.Available at: https://doi.org/10.1016/j.giq.2011.04.005.

Layne, K., \& Lee, J. (2001). Developing fully functional e-government: A four stage model. Government Information Quarterly, $18(2), 122-136$.

Lindgren, I., \& Jansson, G. (2013). Electronic services in the public sector: A conceptual framework. Government Information Quarterly, 30(2), 163-172.Available at: https://doi.org/10.1016/j.giq.2012.10.005.

Lindgren, I., Madsen, C. Ø., Hofmann, S., \& Melin, U. (2019). Close encounters of the digital kind: A research agenda for the digitalization of public services. Government Information Quarterly, 36(3), 427-436.

Performance Report of IEDSL. (2018). Immigration and emigration department, governmnet of Sri Lanka. Retrieved from: http://www.immigration.gov.lk/web/index.php?option=com_content\&view=article\&id=331\&Itemid=218\&lang=en.

Schumachera, A., Erolb, S., \& Sihna, W. (2016). A maturity model for assessing industry 4.0 readiness and maturity of manufacturing enterprises Procedia CIRP, 52(1), 161-166.

Tilson, D., Lyytinen, K., \& Sørensen, C. (2010). Research commentary—Digital infrastructures: The missing IS research agenda. Information Systems Research, 21(4), 748-759.

United Nations. (2020). E-Government survey: Digital government in the decade of action for sustainable development. USA, New York. 